\title{
Variations in anesthetic requirements with body mass index in patients undergoing trans vaginal oocyte retrieval
}

\author{
Dipti Saxena $^{1}$, Bipin Arya ${ }^{1}$, Atul Dixit ${ }^{1}$, Sadhna Sanwatsarkar ${ }^{1}$, Shilpa Bhandari ${ }^{2}$, \\ Pallavi Agrawal ${ }^{2}$
}

\footnotetext{
${ }^{1}$ Department of Anesthesiology, Sri Aurobindo institute of medical sciences \& MOHAK Hi-Tech Hospital, Indore, India

${ }^{2}$ Department of Reproductive Medicine, Sri Aurobindo institute of medical sciences \& MOHAK Hi-Tech Hospital, Indore, India
}

Received: 01 November 2015

Revised: 05 November 2015

Accepted: 14 December 2015

\author{
*Correspondence: \\ Dr. Dipti Saxena, \\ E-mail: diptisaxena08@yahoo.co.in
}

Copyright: () the author(s), publisher and licensee Medip Academy. This is an open-access article distributed under the terms of the Creative Commons Attribution Non-Commercial License, which permits unrestricted non-commercial use, distribution, and reproduction in any medium, provided the original work is properly cited.

\section{ABSTRACT}

Background: Various techniques have been described for ultrasound guided trans-vaginal oocyte retrieval (TVOR). No single technique has been found to be superior to others. In many centers, paracervical block (PCB) is used, either alone or in conjunction with sedation for pain relief during TVOR. This aim of this study is to evaluate the variations in anaesthetic requirements with body mass index (BMI) in patients undergoing transvaginal oocyte retrieval (TVOR).

Methods: This study comprised of 70 women aged between 20 to 40 years. All patients were classified according to WHO classification into four groups on the basis of their BMI. Parameters like effectiveness of paracervical block (PCB), requirement of additional anesthetic drug (propofol), time required for surgery and numbers of oocytes retrieved were studied for each group. The correlation of all these parameters with BMI was noted and statistically evaluated.

Results: PCB alone was not sufficient and all patients required additional propofol for successfully completing the procedure. The requirement of propofol increased with increase in BMI of the patients. The amount of rescue propofol required in patients with $\mathrm{BMI}>30$ was significantly higher as compared to females with $\mathrm{BMI}<30$, irrespective of the time taken during the procedure or the oocyte retrieved. A positive correlation was also observed between number of oocyte retrieved and time taken for surgery.

Conclusions: PCB is quite useful in patients with normal BMI, but it proved to be totally ineffective in obese patients (BMI>30) undergoing TVOR. The requirement of additional propofol and time taken to successfully conduct the procedure is significantly high in patients with high BMI. These alterations in anesthetic parameters with change in BMI have vital implications and they should be taken into consideration while managing obese patients undergoing TVOR.

Keywords: Body mass index, Trans vaginal oocyte retrieval, Para-cervical block, Propofol

\section{INTRODUCTION}

Various techniques have been described for ultrasound guided trans-vaginal oocyte retrieval (TVOR). No single technique has been found to be superior to others. ${ }^{1}$ In many centers, paracervical block (PCB) is used, either alone or in conjunction with sedation for pain relief during TVOR. ${ }^{2}$ Multiple studies comparing different doses of local anesthetic agents used for PCB have been conducted in the past. Dose of lignocaine used in PCB in 
these studies ranged from 50 to $200 \mathrm{mg} .{ }^{3,4}$ All of the previous studies were performed in patients with a similar demographic profile viz BMI, age. Data evaluating the variations in different anesthetic parameters in relation with changes in patient profile is very scarce. Propofol is being used routinely for day care surgeries. It is very suitable anesthetic agent for procedures related to in vitro fertilization. In our institute also we use a combination of PCB and propofol for patients undergoing TVOR. We have observed that requirement of propofol varied over a wide range. The lean and thin patients require very less propofol with PCB as compared to obese patients where large volumes of propofol were required. We, therefore, planned to evaluate different parameters like effectiveness of PCB by assessing the requirement of additional anesthetic drug (propofol), time required for surgery and oocyte retrieval with respect to change in BMI in patients undergoing TVOR.

\section{METHODS}

This prospective study was performed after approval from ethics committee of the institute. Seventy women ASA grade I - II, aged between 24 to 40 years (mean age $29.57 \mathrm{yrs}$ ) were included in the study after obtaining written informed consent. The study was conducted over a period of seven months i.e. from April 2014 to October 2014. All the procedures were performed by same surgeon and anesthesiologist. An informed consent was taken for all the patients prior to the study. The inclusion criteria of the study were presence of follicles in both the ovaries, patients in ASA grade I and II and women up to 40 years of age. The exclusion criteria in terms of anesthesia were patient refusal, history of severe cardiovascular, respiratory or other systemic disease, known history of allergy or sensitivity to any anesthetic drug used in the present study and ASA grade III and IV patients. In terms of infertility history the exclusion criteria included age $>40$ years, Trans abdominal approach for retrieval and women with more than two previous attempts of oocyte retrieval.

The Body Mass Index (BMI) was calculated for all the patients by using standard formula, $\mathrm{BMI}=$ Body mass (in $\mathrm{kg}$ ) / Height (in $\mathrm{m}^{2}$ ) and expressed in units $\mathrm{Kg} / \mathrm{m}^{2}$. All the patients were classified into 4 groups according to BMI as per WHO guidelines as shown in Table 1.

Table 1: Distribution of patients according to BMI (WHO classification).

\begin{tabular}{|lll|}
\hline Group & BMI & Category \\
\hline Group I & $<18.5$ & Underweight \\
\hline Group II & $18.5-24.9$ & Normal weight \\
\hline Group III & $25-29.9$ & Overweight \\
\hline Group IV & $>30$ & Obese \\
\hline
\end{tabular}

\section{Study design}

To assess the effectiveness of PCB we have used fixed volume and concentration of local anesthetic in all the patients. The requirement of additional propofol with change in BMI can help us evaluate the utility and efficacy of PCB in patients belonging to different BMI groups. Time taken for the procedure and number of oocyte retrieved, influence the requirement of propofol. So they were also included in this study.

All patients were fasted for at least $6 \mathrm{hrs}$ and unpremedicated. After being taken in the O.T. all of them received $0.2 \mathrm{mg}$ glycopyrrolate and $1 \mathrm{mg}$ Midazolam. I.V. Fentanyl was administered to all the patients in a dose of $1.5 \mu \mathrm{g} / \mathrm{Kg}$. After painting and draping, paracervical block was performed by the gynecologist using $20 \mathrm{ml}$ of $1 \%$ plain Lignocaine, $10 \mathrm{ml}$ infiltrated on each side. Propofol was administered as an IV bolus of 2 $-3 \mathrm{ml}$ when the block was given. Once the patient stopped responding to verbal command, the procedure was started. Propofol boluses of 2-3 $\mathrm{ml}$ were repeated if patient discomfort was noted. All patients were spontaneously breathing. Oxygen was administered by ventimask and flow was adjusted to 4 lts/ min. Routine monitoring with ECG, $\mathrm{HR}, \mathrm{SPO}_{2}$ and non-invasive $\mathrm{BP}$ was done. At the end of the procedure, total volume of propofol required, number of oocytes retrieved and time taken were noted. Time taken was calculated from administration of the block to the last oocyte retrieved.

\section{RESULTS}

The results were analyzed and frequency tables of all variables were drawn. Cross tabulations of all variables with outcome was done. The statistical analysis was done using software SPSS and STATISTICA. Results in text and tables are expressed as mean $\pm \mathrm{SE}$, number/percentage within group or median (range) as appropriate. Correlation coefficients between different parameters were analyzed and appropriate graphs were drawn as per the results. Regression analysis, one way ANOVA and student $t$ test were used in order to assess impact of independent variables.

The data collected in this study consisted of BMI, volume of propofol given, time taken for the procedure and number of oocytes retrieved. Maximum number of patients in our study belonged to group II (normal weight). Most of the patients belonged to the age group of 28 to 35 years.

The data was analyzed and results as tabulated in Table 2 were obtained. Student $t$ test was used to correlate various parameters within the groups as mentioned in Table 3.

(a) Correlation of BMI with propofol: A very strong positive correlation was observed between various groups of BMI and dose of propofol required for the procedure with $(\mathrm{r}=0.9939)$ and the regression line $(\mathrm{Y}=1.318$ $+4.2882 \mathrm{X})$ 
Table 2: Observed values of various anesthetic parameters in different groups.

\begin{tabular}{|llclll|}
\hline Groups & $\begin{array}{l}\text { No of } \\
\text { Patients }\end{array}$ & BMI (avg) & $\begin{array}{l}\text { Avg. Propofol } \\
\text { required (mg) }\end{array}$ & $\begin{array}{l}\text { Avg. Time taken } \\
(\text { min) }\end{array}$ & Avg. Oocytes retrieved \\
\hline I & 12 & 18.0833 & 80 & 16.5 & 18.5833 \\
\hline II & 30 & 22.02 & 92.3333 & 17.4667 & 17.0333 \\
\hline III & 19 & 26.6526 & 118.9474 & 17.7895 & 18.7368 \\
\hline IV & 9 & 32.33 & 138.8889 & 25.6667 & 20.8889 \\
\hline Average & & 24.77148 & 107.5424 & 19.35573 & 18.81058 \\
\hline Standard error & & 6.136563 & 26.47375 & 4.242839 & 1.584849 \\
\hline
\end{tabular}

Table 3: Statistical correlation of various parameters within different study groups.

\begin{tabular}{|llllll|}
\hline Groups & $\begin{array}{l}\text { Correlation } \\
\text { between propofol } \\
\text { and BMI }\end{array}$ & $\begin{array}{l}\text { Correlation } \\
\text { between time and } \\
\text { propofol }\end{array}$ & $\begin{array}{l}\text { Correlation } \\
\text { between BMI } \\
\text { and Time }\end{array}$ & $\begin{array}{l}\text { Correlation between } \\
\text { oocytes and propofol }\end{array}$ & $\begin{array}{l}\text { Correlation } \\
\text { between } \\
\text { oocytes and } \\
\text { time }\end{array}$ \\
\hline I & Not significant & $\begin{array}{l}\text { Significant } \\
(\mathrm{p}=0.0036)\end{array}$ & Not significant & $\begin{array}{l}\text { Significant } \\
(\mathrm{p}=0.00218)\end{array}$ & $\begin{array}{l}\text { Significant } \\
\text { (p=0.0018) }\end{array}$ \\
\hline II & Not significant & $\begin{array}{l}\text { Significant } \\
(\mathrm{p}=1.899 \mathrm{E}-05)\end{array}$ & Not significant & $\begin{array}{l}\text { Significant } \\
(\mathrm{p}=6.321 \mathrm{E}-05)\end{array}$ & $\begin{array}{l}\text { Significant } \\
\text { (p=4.508E-09) }\end{array}$ \\
\hline III & Not significant & $\begin{array}{l}\text { Significant } \\
(\mathrm{p}=0.0004)\end{array}$ & Not significant & $\begin{array}{l}\text { Significant } \\
(\mathrm{p}=4.0618 \mathrm{E}-05)\end{array}$ & $\begin{array}{l}\text { Significant } \\
\text { (p=1.455E-05) }\end{array}$ \\
\hline IV & Not significant & Not significant & Not significant & Not significant & Not significant \\
\hline
\end{tabular}

(b) Correlation of BMI with time taken: A strongly positive correlation was noted between different BMI groups and time taken to complete the procedure $(\mathrm{r}=$ 0.88405 and $\mathrm{y}=\mathrm{Y}=4.2139+0.6113 \mathrm{X})$. The time taken to complete the procedure increased with rise in BMI of the patients.

(c) Correlation of propofol required and time taken: A strongly positive correlation was also found between dose of propofol required and the time taken to complete the procedure $(\mathrm{r}=0.8527$ and $\mathrm{Y}=4.6595+0.1367 \mathrm{X})$.

(d) Correlation between oocyte retrieved and BMI: The number of oocytes retrieved during the procedure did not depend on the BMI of the patient and there was no major difference between oocyte retrieved in each BMI group.

P-value for $\mathrm{f}$ test in one way ANOVA was 0.005463 which is $<0.01$ suggesting statistically significant difference of propofol requirement between the four groups.

\section{DISCUSSION}

Trans Vaginal Oocyte Retrieval (TVOR) may be the most painful component of IVF treatment but has attracted very limited attention in the literature. Perception of pain and discomfort during TVOR is an important issue to be addressed. The optimal anaesthetic method should provide rapid onset of anaesthesia with adequate anaesthesia during the procedure, followed by a rapid recovery. ${ }^{5}$

In this study, we used the fixed volume and concentration of local anesthetic for PCB in all the patients. The efficacy of PCB was measured by total volume of rescue intravenous propofol required to successfully complete the procedure. The requirement of additional propofol with change in BMI thus helped us evaluate the utility and efficacy of PCB in patients belonging to different BMI groups.

All the patients in different BMI groups required propofol indicating inefficacy of PCB as a sole anesthesia technique for TVOR. Ernest Hung $\mathrm{Yu} \mathrm{Ng}$ et al have recommended the use of both conscious sedation and PCB for better pain control. ${ }^{4,6}$ Similar observations were made in our study. PCB, if effective, reduces the requirement of propofol. Christiaens et al have reported doses up to $10 \mathrm{mg} / \mathrm{kg}$ while Sholomo et al have used propofol doses up to $5 \mathrm{mg} / \mathrm{kg}^{7,8}$ In our study the requirement of propofol was maximum up to $3.7 \mathrm{mg} / \mathrm{kg}$.

Chassard et al has shown that propofol requirement (total dose) was not proportional to weight or age but related to lean body mass and to BMI in patients undergoing gynecologic surgery. ${ }^{9} \mathrm{We}$ have found that amount of rescue propofol required in patients undergoing TVOR and the time required for the procedure show linear 
correlation when different BMI groups are compared and the correlation coefficients are significantly high. No correlation, however, could be established between propofol required and BMI while evaluating patients belonging to same BMI group. Interestingly, when group I was compared to group IV significant increase in propofol requirement was observed $(\mathrm{p}<0.01)$.

The correlation between time taken for the procedure and amount of rescue propofol required in Groups I, II and III was found to be significant (Table 3). This again suggested that PCB is ineffective as sole anesthesia modality and additional anesthetic agent like propofol is required for optimum effect. It is important to note that in obese patients (group IV) the requirement of propofol is independent of the number of oocytes harvested or time taken. Frequent boluses of propofol are required during the procedure as discomfort is noted despite PCB in patients with high BMI.

Irrespective of the number of oocyte retrieved the time taken for the procedure is distinctly higher in obese patients $(\mathrm{p}<0.01)$. This can be attributed to the fact that the procedure becomes technically difficult even in experienced hands and access to ovary is limited. Multiple punctures may be required to reach the ovary for oocyte retrieval. Thus, PCB fails in obese patients justifying the higher rescue propofol requirement in these patients. In obese patients likelihood of propofol reaching higher concentration in oocytes is more. Recent literature suggests that although it gets concentrated in follicular fluid, no detrimental effect has been shown on oocyte quality and fertilization rates. ${ }^{7,10}$ Still, concerns regarding its deleterious effects on oocytes persist when higher doses are used.

Larger studies are required to validate the efficacy of PCB in patients with high BMI. Sub arachnoid block despite being technically difficult, may be a better alternative in such patients. With obesity becoming an epidemic, relevance of such studies cannot be refuted. Egan et al in their study have concluded that TVOR and the use of total intravenous anesthesia were less common with increasing BMI. None of the patients managed with spinal anesthesia in their study experienced intraoperative desaturation or required conversion to general anaesthesia with endotracheal intubation. ${ }^{11}$ In our study although desaturation was seen in overweight and obese patients but they were easily managed by triple airway manoeuvre and placement of oral airway. No conversion to general anesthesia was required.

\section{CONCLUSIONS}

This study concludes that PCB although quite useful in patients with normal BMI, proved totally ineffective in obese patients (BMI>30) undergoing TVOR. The requirement of additional propofol and time taken to successfully complete the procedure is significantly high in patients with BMI $>30$. This may increase the likelihood of higher propofol concentrations in oocytes in these patients.

\section{ACKNOWLEDGEMENTS}

Dr. Advait Prakash,, Associate Professor, Pediatric Surgery for his help in statistical analysis, manuscript preparation and editing.

Funding: No funding sources

Conflict of interest: None declared

Ethical approval: The study was approved by the Institutional Ethics Committee

\section{REFERENCES}

1. Kwan I, Bhattacharya S, Knox F, Alex McNeil A. Conscious sedation and analgesia for oocyte retrieval during IVF procedures: a Cochrane review. Hum Reprod. 2006;21(7):1672-9.

2. Ng EH, Chui DK, Tang OS, Ho PC. Para cervical block with and without conscious sedation: a comparison of the pain levels during egg collection and the postoperative side effects. Fertil Steril. 2001;75(4):711-7.

3. Ng EH, Miao B, Ho PC. A randomized double-blind study to compare the effectiveness of three different doses of lignocaine used inparacervical block during oocyte retrieval. J Assist Reprod Genet. 2003;20(1):8-12.

4. Ng EH, Tang OS, Chui DK, Ho PC Comparison of two different doses of lignocaine used in paracervical block during oocyte collection in an IVF programme. Hum Reprod. 2000;15(10):2148-51.

5. Bumen S, Gunuşen I, Firat V, Karaman S, Akdoğan A, Goker ENT. A comparison of intravenous general anesthesia and paracervical block for in vitro fertilization: effects on oocytes using the transvaginal technique. Turk J Med Sci 2011;41(5):801-8.

6. Ng EH, Tang OS, Chui DKC, Ho PC. A prospective, randomized, double-blind and placebo controlled study to assess the efficacy of paracervical block in the pain relief during egg collection in IVF. Hum Reprod.1999;14(11):2783-7.

7. Christiaens F, Janssenswillen C, Verborgh C, Moerman I, Devroey P, Van Steirteghem A et al Propofol concentrations in follicular fluid during general anaesthesia for transvaginal oocyte retrieval. Hum Reprod. 1999;14(2):345-8.

8. Ben-Shlomo I1, Moskovich R, Golan J, Eyali V, Tabak A, Shalev E. The effect of propofol anaesthesia on oocyte fertilization and early embryo quality. Hum Reprod. 2000;15(10):2197-9.

9. Chassard D, Berrada K, Bryssine B, Guiraud M, Bouletreau P. Influence of body compartments on propofol induction dose in female patients. Acta Anaesthesiol Scand. 1996;40(8):889-91.

10. Matsota P, Sidiropoulou T, Batistaki C, Giannaris D, Pandazi A, Krepi $\mathrm{H}$, et al. Analgesia with remifentanil versus anesthesia with propofol- 
alfentanil for transvaginal oocyte retrieval: a randomized trial on their impact on in vitro fertilization outcome. Middle East J Anaesthesiol. 2012;21(5):685-92.

11. Egan B, Racowsky C, Hornstein MD, Martin R, Tsen LC. Anesthetic impact of body mass index in patients undergoing assisted reproductive technologies. J Clin Anesth. 2008;20(5):356-63.
Cite this article as: Saxena D, Arya B, Dixit A, Sanwatsarkar S, Bhandari S, Agrawal P. Variations in anesthetic requirements with body mass index in patients undergoing trans vaginal oocyte retrieval. Int J Reprod Contracept Obstet Gynecol 2016;5:135-9. 